\title{
THERMAL EXPANSION OF LEAD
}

\author{
By Peter Hidnert and W. T. Sweeney
}

ABSTRACT

Measurements have been made on the linear thermal expansion of three samples of cast lead between room temperature and $300^{\circ} \mathrm{C}$. and the results have been correlated with data obtained by other investigators between 1740 and 1931 .

A curve has been derived which shows the linear thermal expansion of lead between $-253^{\circ}$ and $+300^{\circ} \mathrm{C}$. The summary gives average coefficients of expansion for various temperature ranges between $-250^{\circ}$ and $+300^{\circ} \mathrm{C}$.

A comparison of the indirect results by Kopp and Matthiessen with the direct data by other observers, indicates that lead expands the same in all directions.

\section{CONTENTS}

I. Introduction

II. Materials investigated

III. Apparatus

IV. Results_... 706

V. Summary

\section{INTRODUCTION}

The thermal expansion of lead has been of considerable interest for nearly 200 years. Its measurement has been the object of more than 25 investigations. A summary of available data obtained by various investigators is given in Table 1.

Between 1740 and 1831, a number of determinations of the coefficient of linear expansion were made for the range from $0^{\circ}$ to $100^{\circ} \mathrm{C}$. In 1831, Daniell reported the changes in length of a bar of lead heated from $17^{\circ}$ to $100^{\circ} \mathrm{C}$. and to the point of fusion, respectively. From that time up to 1930 , no measurements on the linear thermal expansion of lead above $110^{\circ} \mathrm{C}$. have been located in the literature. The present authors appear to have been the first observers after Daniell to report data on the linear thermal expansion of lead above $110^{\circ} \mathrm{C}$. Their abstract giving coefficients of linear expansion on heating for various temperature ranges between $20^{\circ}$ and $300^{\circ} \mathrm{C}$. was published ${ }^{1}$ in February, 1930. In October of the same year, Uffelmann ${ }^{2}$ published coefficients of linear expansion for various temperatures between $80^{\circ}$ and $280^{\circ} \mathrm{C}$.

The present investigation was undertaken in order to obtain reliable data on the linear thermal expansion of lead above $100^{\circ} \mathrm{C}$. The data obtained between $20^{\circ}$ and $300^{\circ} \mathrm{C}$. have been correlated with results by other observers.

The authors wish to express appreciation to H. W. Bearce, W. Souder, and H. S. Rawdon for valuable suggestions, and to H. S. Krider for assistance during the preparation of the manuscript. 


\begin{tabular}{|c|c|c|c|c|c|c|c|c|}
\hline 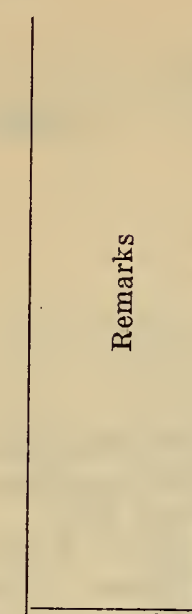 & 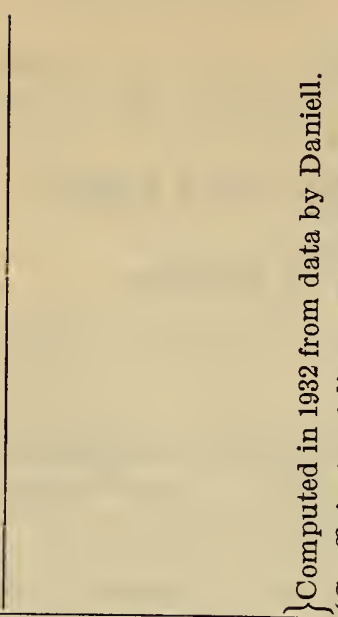 & 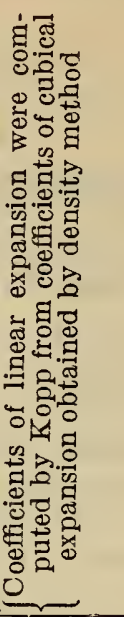 & 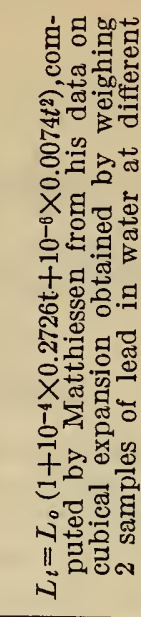 & 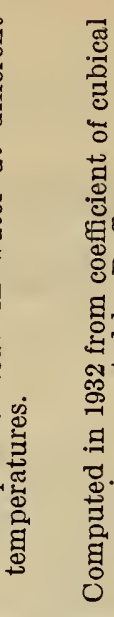 & 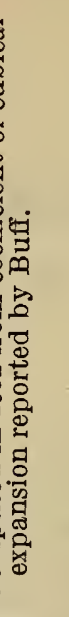 & & 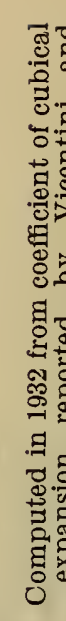 & \\
\hline 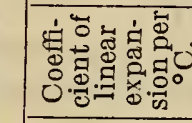 & 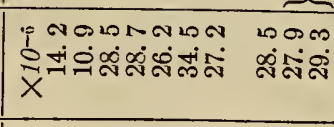 & 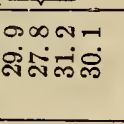 & $\begin{array}{l}0 \\
\substack{\infty \\
\infty} \\
\infty\end{array}$ & $\begin{array}{l}\text { Nका } \\
\text { क्षंक्ष }\end{array}$ & $\overrightarrow{\text { ลे }}$ & $\begin{array}{ll}\text { में } \\
\text { के }\end{array}$ & के & 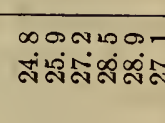 \\
\hline 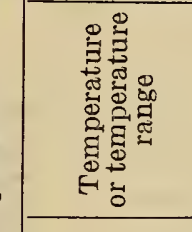 & 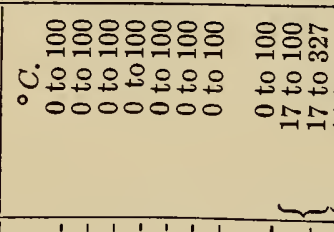 & 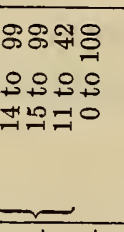 & 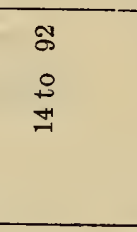 & 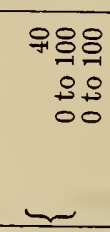 & $\begin{array}{l}8 \\
0 \\
0 \\
0\end{array}$ & 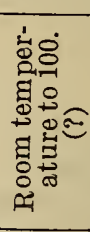 & జ్లి & 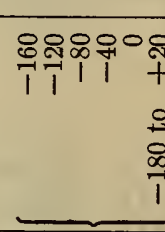 \\
\hline 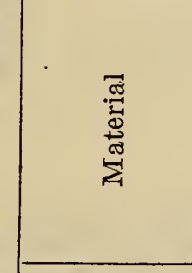 & 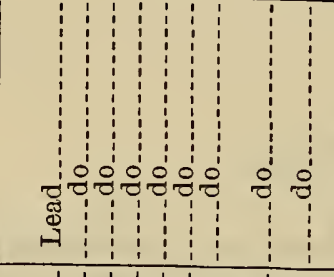 & 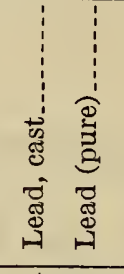 & 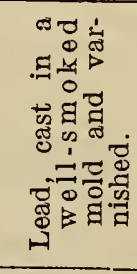 & 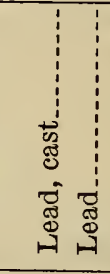 & 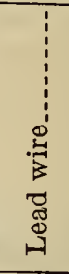 & 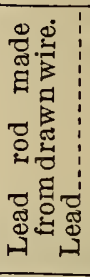 & ì & 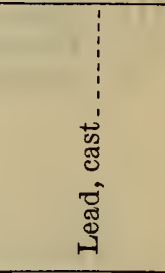 \\
\hline 怤 & 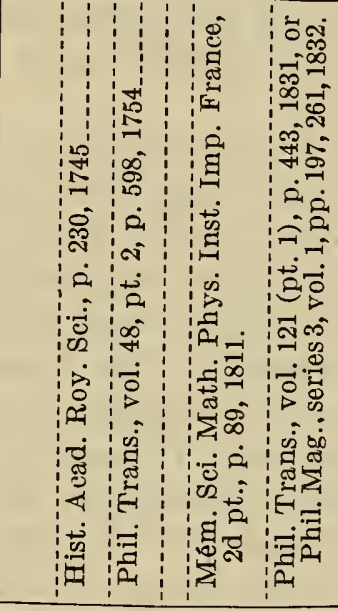 & 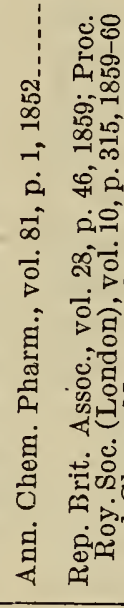 & 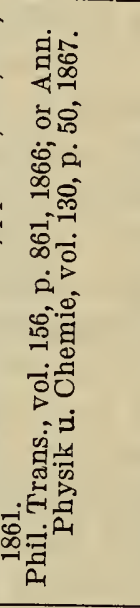 & 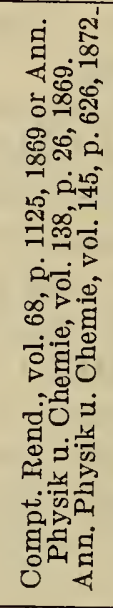 & 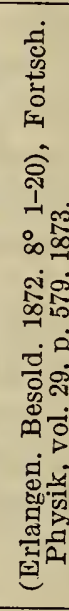 & 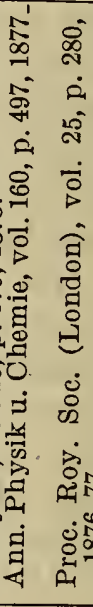 & 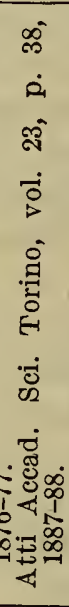 & 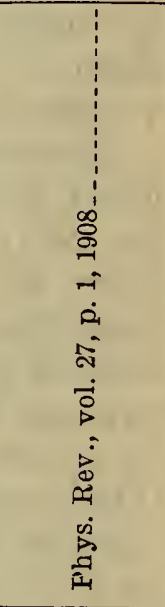 \\
\hline 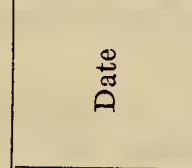 & 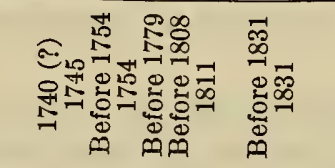 & 祝 & $\underset{\infty}{\mathscr{\sim}}$ & 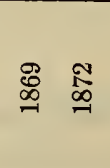 & $\underset{\substack{\mathbb{N} \\
\sim}}{\mathbb{N}}$ & 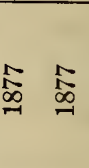 & $\begin{array}{l}\infty \\
\stackrel{\infty}{\infty}\end{array}$ & $\stackrel{\infty}{\circ}$ \\
\hline 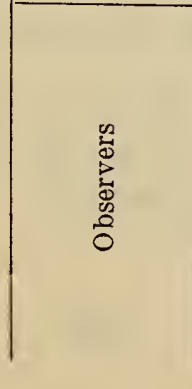 & 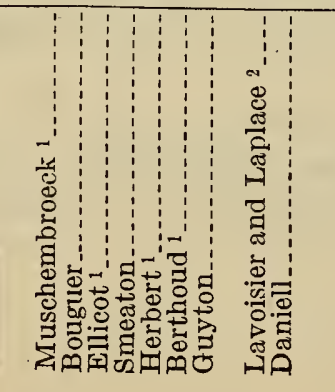 & 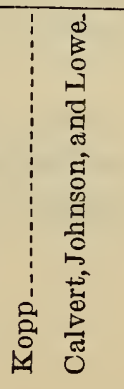 & 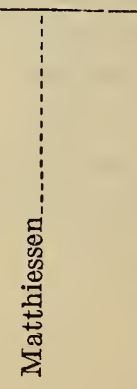 & 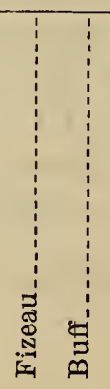 & 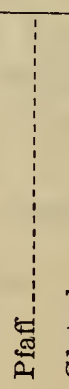 & 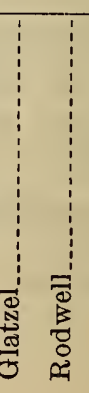 & 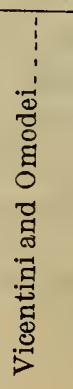 & 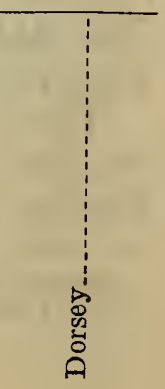 \\
\hline
\end{tabular}




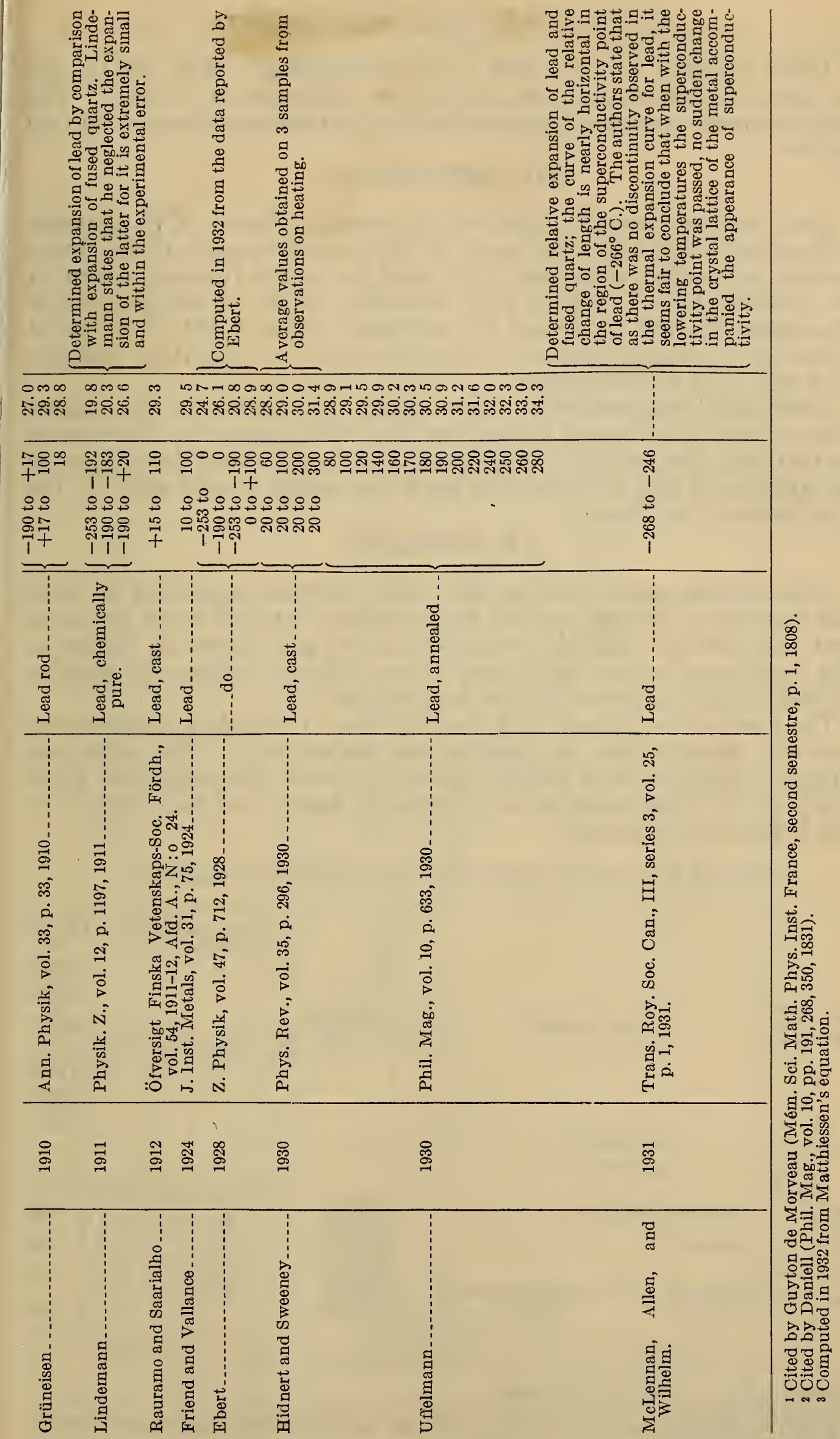




\section{MATERIALS INVESTIGATED}

Three samples of cast lead were investigated. The purity and the method of casting of the samples are indicated in Table 2. The length of each sample was about $300 \mathrm{~mm}$ and the cross section $10 \mathrm{~mm}$ square.

\section{APPARATUS}

The furnace shown in Figure 1 of Scientific Paper of the Bureau of Standards No. 488, was used for the measurements of the linear thermal expansion of sample 1001 and the white furnace shown at the extreme left of Figure 1 of Scientific Paper of the Bureau of Standards No. 524 was used for samples 1144 and 1215 . Figure 4 of the latter paper indicates the method used in mounting samples 1144 and 1215 in the furnace.

Expansion measurements were made by means of micrometer microscopes, which were sighted on fine wires suspended from or in contact with the ends of the specimen. For a detailed description of the apparatus and the methods used the reader should refer to the publications mentioned.

\section{RESULTS}

Observations were made on the linear thermal expansion of three cast samples of lead at various temperatures between room temperature and $300^{\circ} \mathrm{C}$. and the results obtained are shown in Figure 1. The expansion curves are plotted from different origins to display the individual characteristics of each curve.

The average coefficients of expansion given in Table 2 were derived from the observations on heating and on cooling. This table also gives the differences in length before and after the expansion tests. The plus $(+)$ sign indicates an increase in length and the minus $(-)$ sign a decrease in length.

TABLE 2.-Average coefficients of linear expansion of cast lead

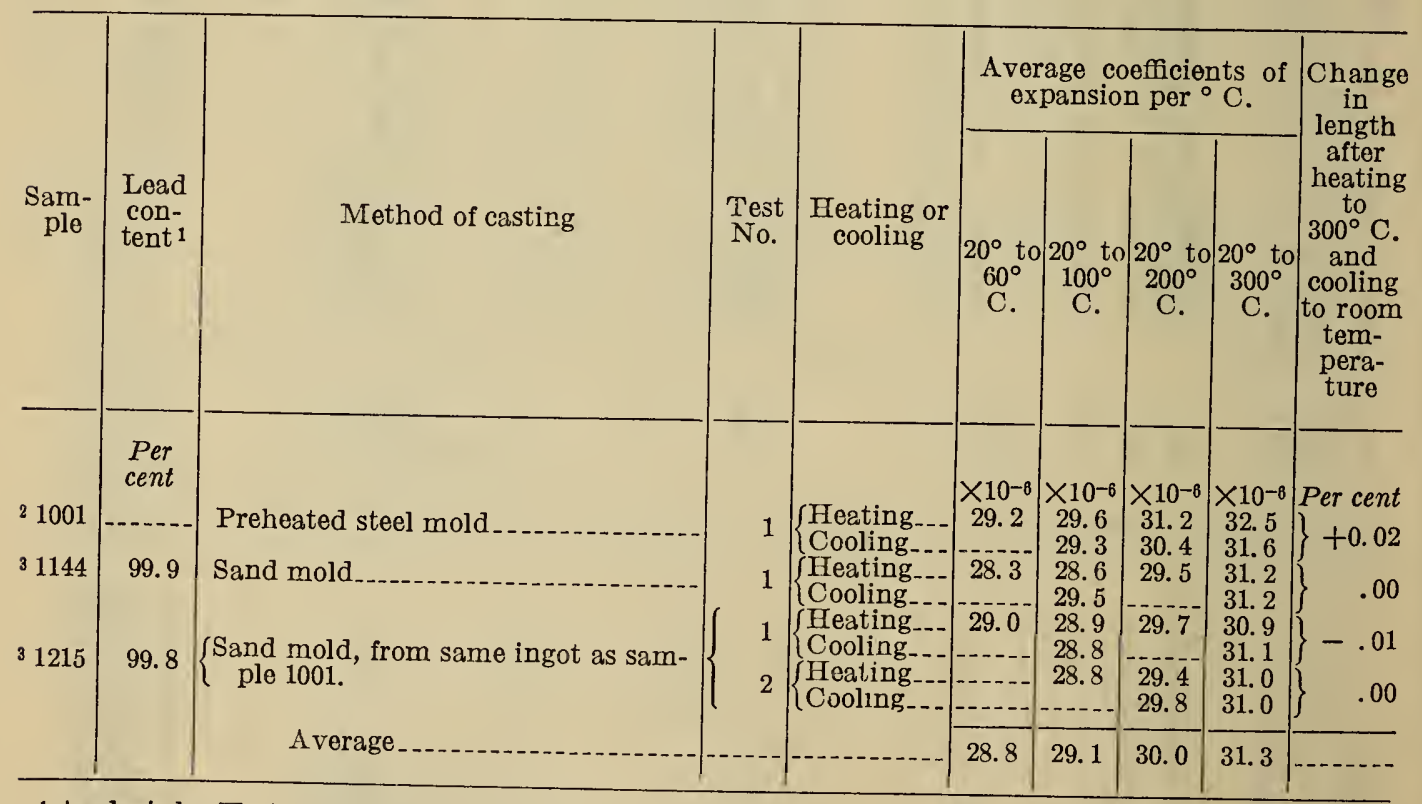

1 Analysis by H. A. Buchhert, of this bureau.

2 See sample 1215. 3 Density for samples 1144 and $1215,11.310$ and $11.329 \mathrm{~g} / \mathrm{cm}^{3}$ at $25^{\circ} \mathrm{C}$, respectively, determined by Miss
E. E. Hill, of this bureau. 
The differences obtained in the coefficients of expansion of the three samples of cast lead are probably due to variations in the methods of casting.

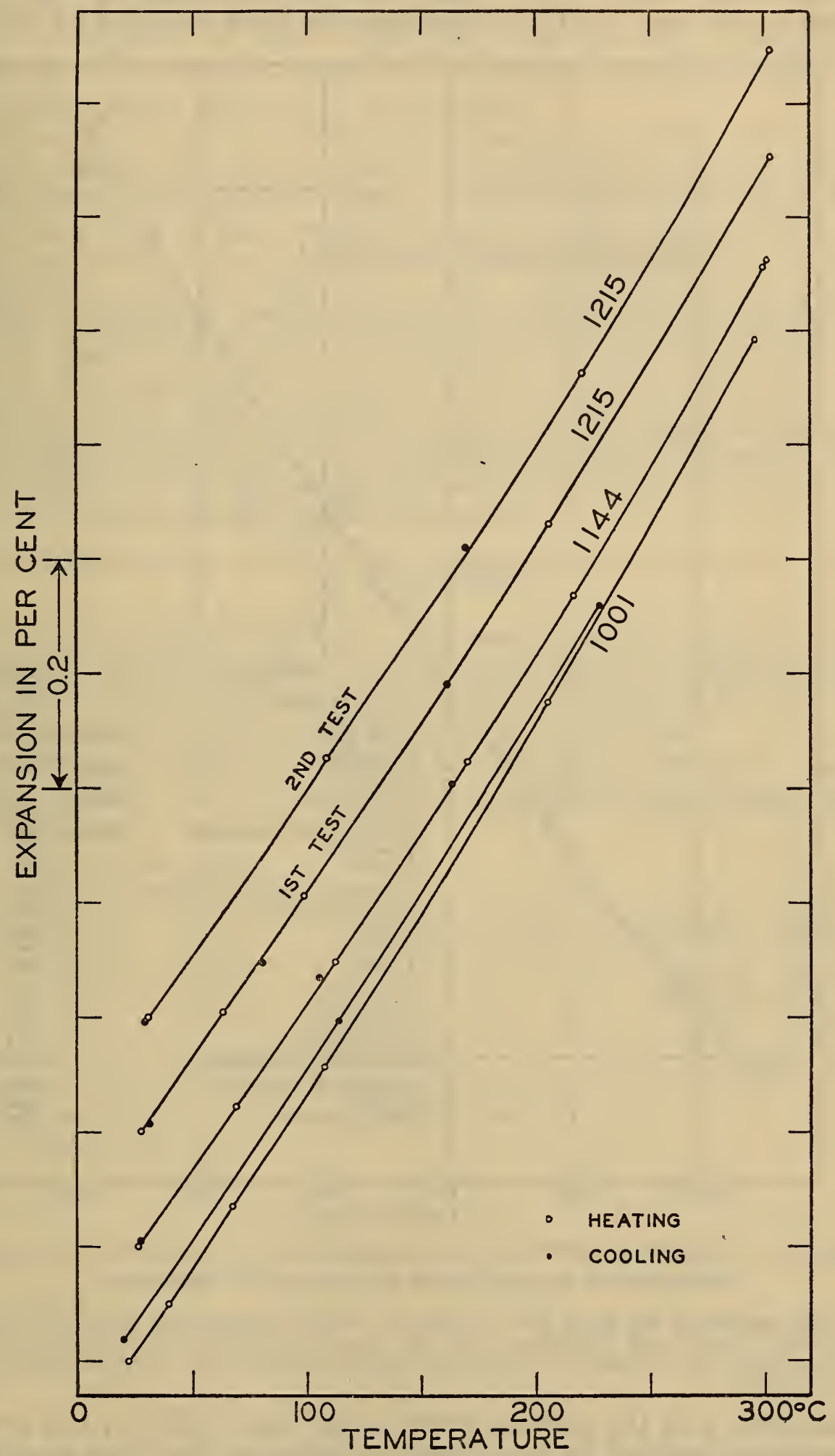

FIGURE 1.-Linear thermal expansion of three cast samples of lead

Sample 1001 which was cast in a preheated steel mold, has larger coefficients of expansion than the samples cast in sand molds. From the observations obtained on cooling, it appears that the coefficients 
of expansion of sample 1001 on the next heating would be less than those obtained on the first heating.

The curve in Figure 2 represents the linear thermal expansion of lead between $-253^{\circ}$ and $+300^{\circ} \mathrm{C}$. The portion of the curve between $-253^{\circ}$ and $+20^{\circ} \mathrm{C}$. represents the data obtained by previous

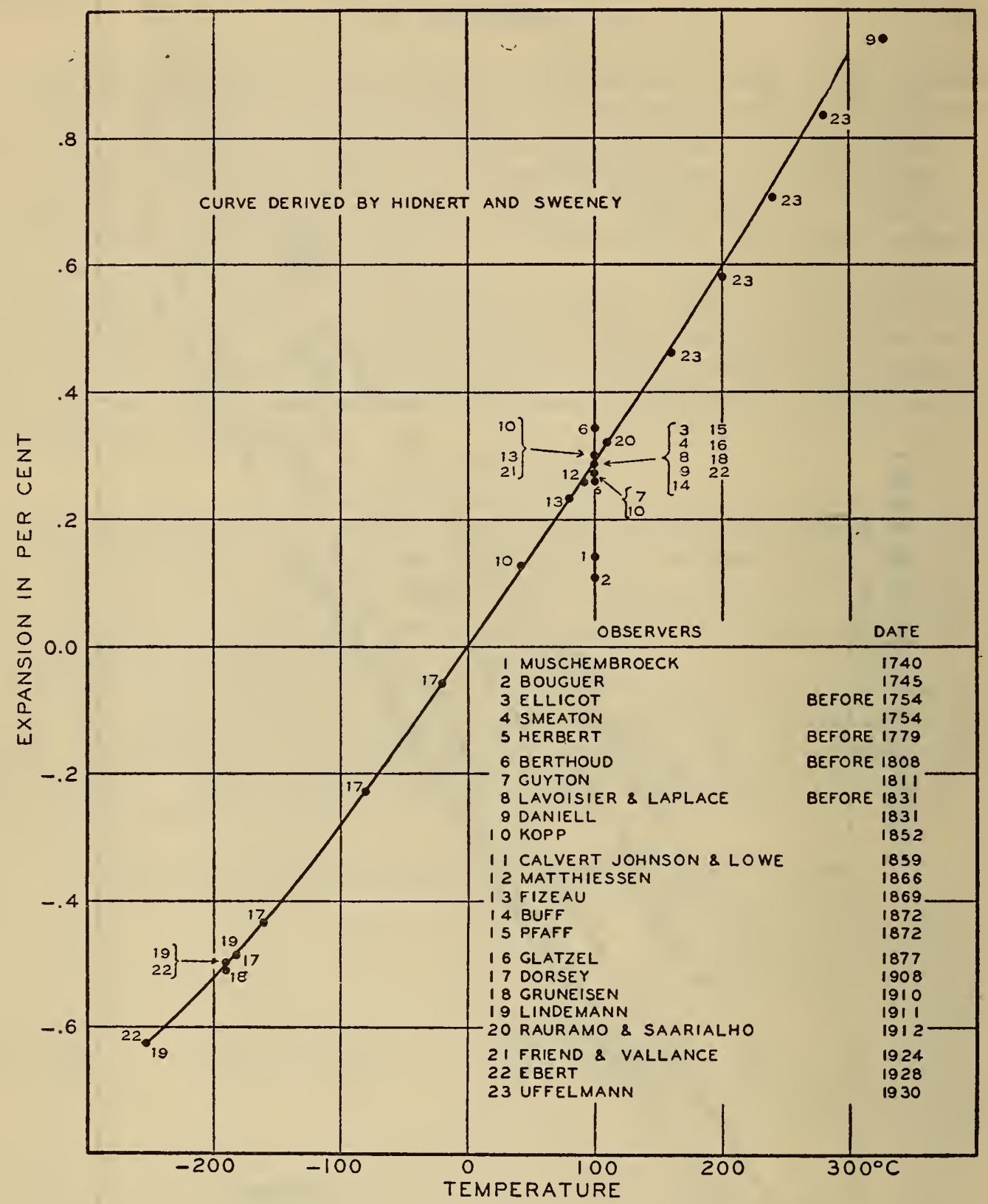

Figure 2.-Cómparison of the average expansion curve derived in the present investigation on lead, with data from the observers

The lower portion of the curve from $-253^{\circ}$ to $+20^{\circ} \mathrm{C}$. was derived from data by Lindemann, Ebert, Dorsey, and Grüneisen, and the upper portion of the curve from $20^{\circ}$ to $300^{\circ} \mathrm{C}$. represents the average of all results obtained in the present investigation on three samples of lead.

investigators, and the portion between $20^{\circ}$ and $300^{\circ} \mathrm{C}$., the average of all results obtained by the present authors on the three samples of lead. The values obtained by other observers are included in this figure for comparison. Most of these values show good agreement. Bouguer and Muschembroeck obtained the lowest values and Berthoud the highest value at $100^{\circ} \mathrm{C}$. 
Kopp and Matthiessen's data for linear expansion obtained indirectly from density measurements agree closely with direct measurements made by other observers, and therefore it appears that the expansion of lead is the same in all directions.

The coefficient of linear expansion derived from Vicentini and Omodei's value for the coefficient of cubical expansion of lead near the melting point, appears to be too low.

McLennan, Allen, and Wilhelm published a curve which shows the relative change of length measured against the change of length of fused quartz near absolute zero. Their conclusion relating to the lattice structure of lead, which is based on the assumption that the expansion curve of lead is almost horizontal in the region of the superconductivity point $\left(-266^{\circ} \mathrm{C}\right.$.), does not appear to be justified. Since the expansion of fused quartz is not known near absolute zero, it is not possible definitely to determine from their curve the actual expansion of lead in this region. It is possible that when these observers cooled lead and fused quartz in the region of the superconductivity point of lead, the contraction of the lead nearly balanced the expansion of the fused quartz ${ }^{3}$ and thus they obtained a nearly horizontal curve for the relative expansion.

\section{SUMMARY}

Data have been obtained on the linear thermal expansion of three samples of cast lead. Observations were taken at various temperatures between room temperature and $300^{\circ} \mathrm{C}$., and the data have been correlated with available data by other investigators.

The average coefficients of linear expansion for various temperature ranges between $-250^{\circ}$ and $+300^{\circ} \mathrm{C}$., as derived from the expansion curve in Figure 2 are as follows:

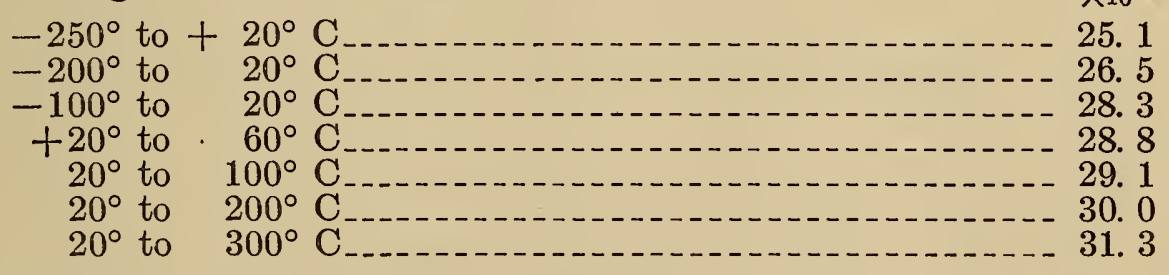

WASHINGroN, September 12, 1932.

${ }^{3}$ Souder and Hidnert, B. S. Sci. Paper No. 524 (fig. 11).

$141809-32-9$ 